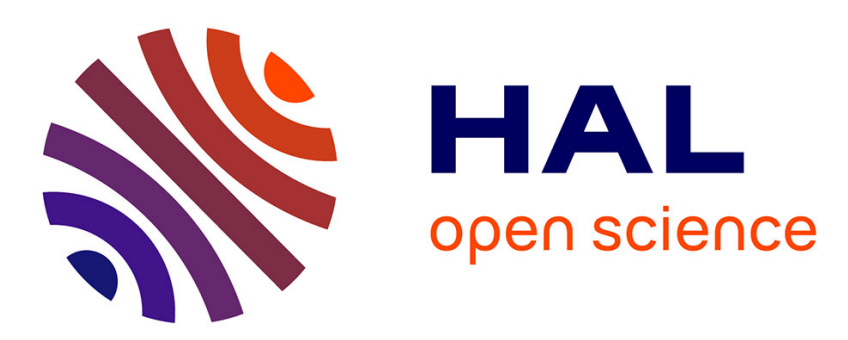

\title{
Micro-movement as physical signature of movement intention in work of choreographer Myriam Gourfink
}

Rebecca Warzer, Elizabeth Torres, Asaf Bachrach

\section{To cite this version:}

Rebecca Warzer, Elizabeth Torres, Asaf Bachrach. Micro-movement as physical signature of movement intention in work of choreographer Myriam Gourfink. International Workshop on Movement and Computing, IRCAM, Jun 2014, paris, France. pp.156 - 157, 2014, 10.1145/2617995.2618024 . hal01100680

\section{HAL Id: hal-01100680 \\ https://hal.science/hal-01100680}

Submitted on 6 Jan 2015

HAL is a multi-disciplinary open access archive for the deposit and dissemination of scientific research documents, whether they are published or not. The documents may come from teaching and research institutions in France or abroad, or from public or private research centers.
L'archive ouverte pluridisciplinaire HAL, est destinée au dépôt et à la diffusion de documents scientifiques de niveau recherche, publiés ou non, émanant des établissements d'enseignement et de recherche français ou étrangers, des laboratoires publics ou privés. 


\section{Micro-movement as physical signature of movement intention in work of choreographer Myriam Gourfink}

Rebecca Warzer Bennington College Bennington, VT, USA
Elizabeth B. Torres

Cognitive Psychology \& Computational Neuroscience

Rutgers University

New Brunswick, NJ, USA
Abstract

A micro-movement paradigm that distinguishes goal-directed from goal-less movement in Autistic children was adapted to study intentionality of movement in dancers. Dancers were trained in Myriam Gourfink's technique, whose work is characterized by constant and heightened awareness of the body and its movement. In past studies using the forwardand-retracting structure of pointing motions [2], hhe instructed motor segment deliberately intended toward the target had a statstical sgnathe of inter (n)

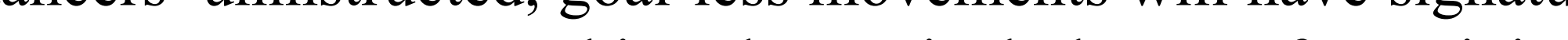

\section{Introduction}

Torres et al. use the term micro-movement to describe the statistical microstructure of body movement inherent in the variability of velocity- or acceleration-dependent parameters in the continuous flow of motion trajectories. These can b measured with wearable sensing technology such as accelerometers, and analyzed with a newly developed technique [4]

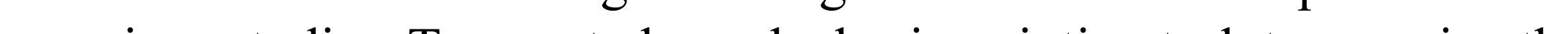

In previous studies, Torres et al. used a basic pointing task to examine the statistical signatures of goal-directed and goalless motor segments [4]. In comparing he micro-movements of the pointing task across many different repetitions of the (lask 列 Ad sensitive to exprim

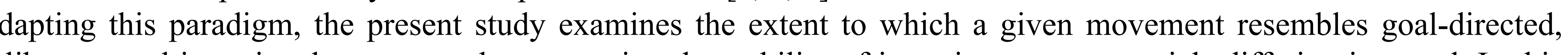
列

\section{Materials \& Methods}

In the pointing experiment, dancers were instructed to point at a target on the wall (a black " $\mathrm{X}$ " 4 inches across) in response to a tone. Each tone that was played was one of four different pitches, and dancers were instructed to point faster in response to a higher pitch, and slower in response to a lower pitch. Varying pointing speed allows the pointing trajectory to be studied across different contexts, and using different pitches to accomplish this was the method that was least invasive to our study. Each pitch was played 25 times in a randomized order, yielding 100 trials per experiment. Each tone was $750 \mathrm{~ms}$ long, and tones were separated by a randomly chosen interval of time between 4 and 8 seconds to hamper dancers' ability to predict the regular occurrence of a tone. Movement trajectory was measured with an inertia measurement unit (IMU) consisting of an accelerometer and a gyroscope at a sampling rate of $200 \mathrm{~Hz}$. Data from the IMUs were recorded using a Max/MSP patch developed in-house. We used 10 IMUs that were paired in units of two for each subject. One IMU was worn on the pointing hand of the subject and the other worn on the subject's head.

\section{A}

ESTIMATED GAMMA PARAMS

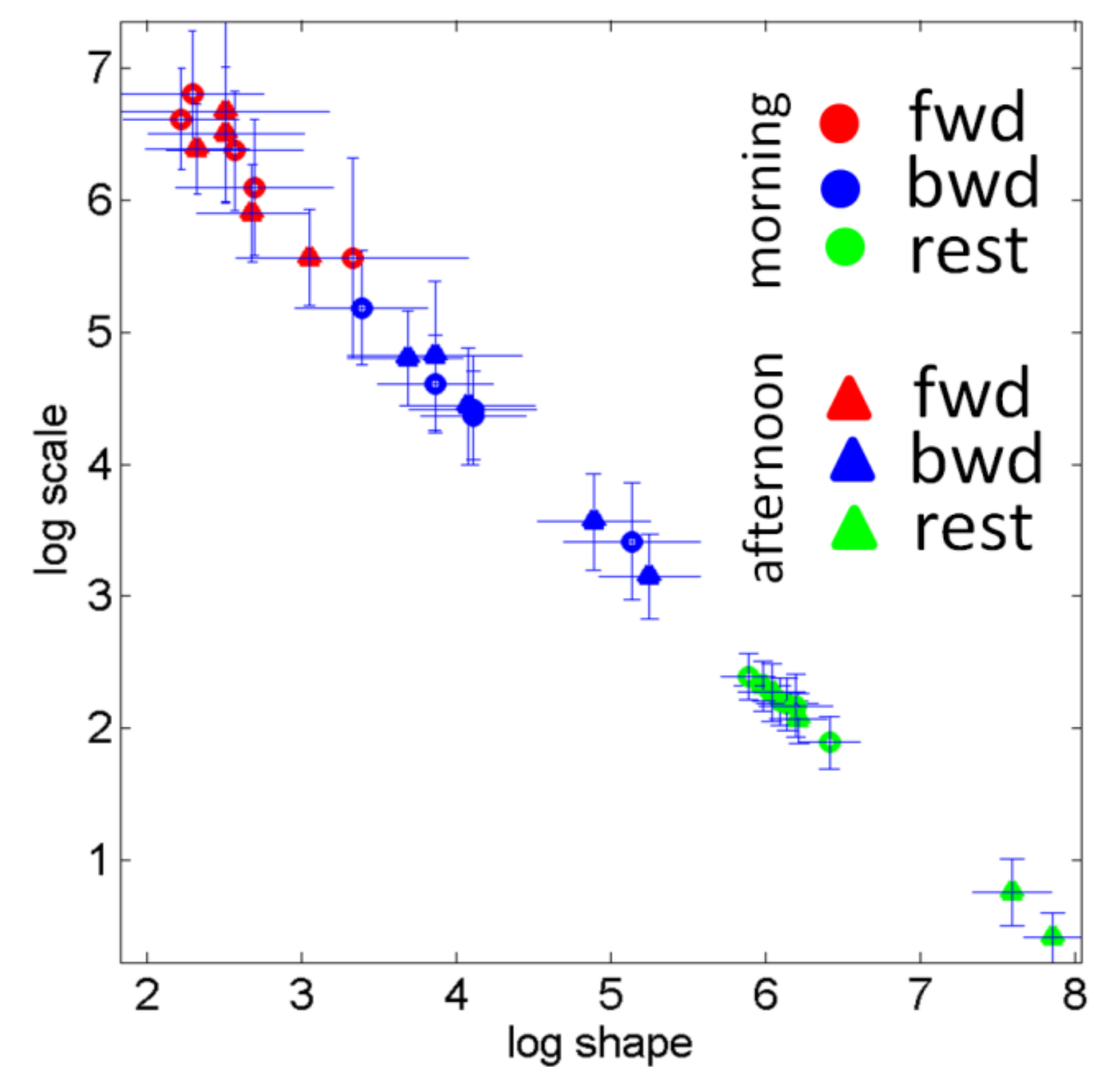

B

GAMMA STATS

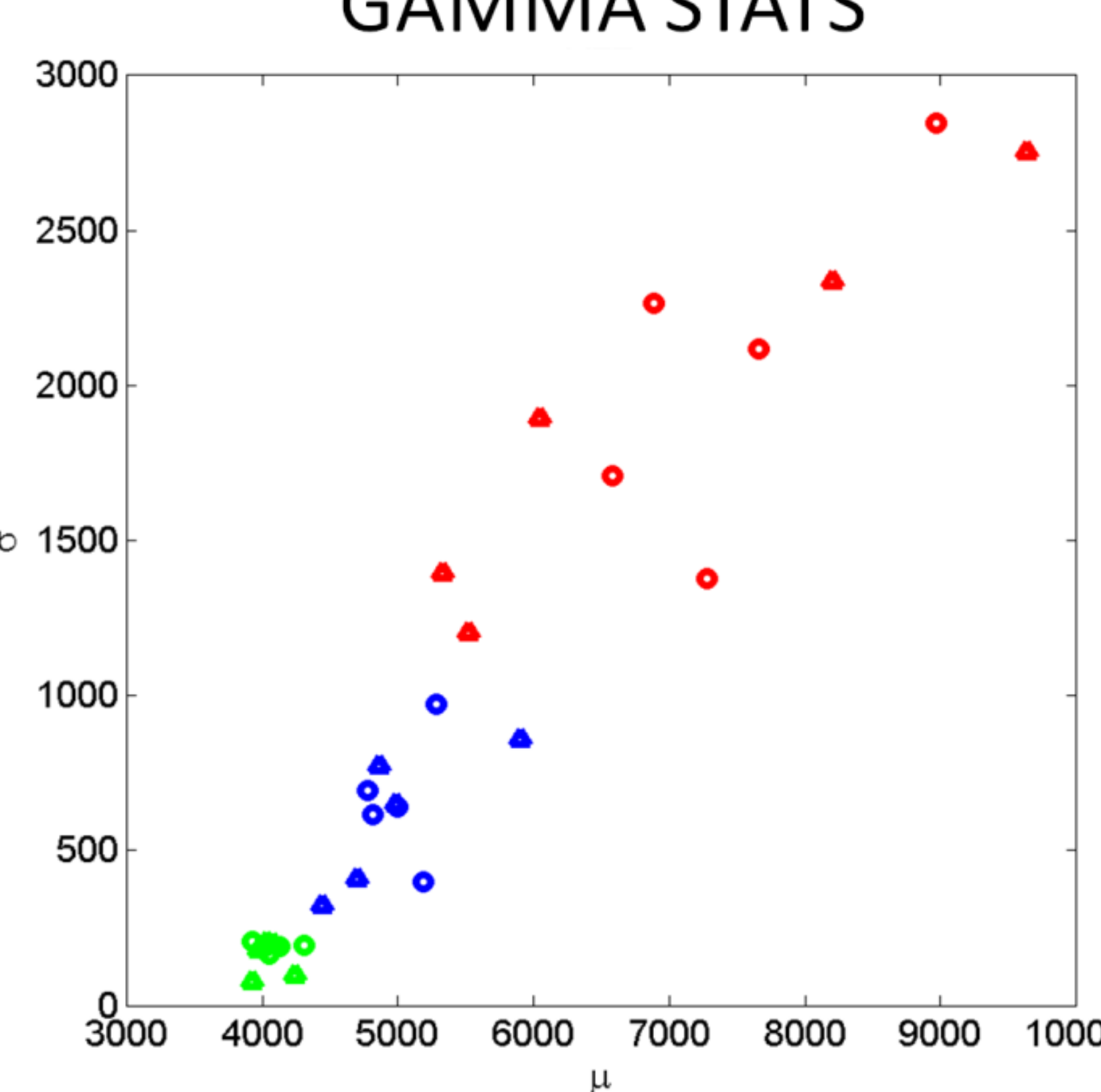

A

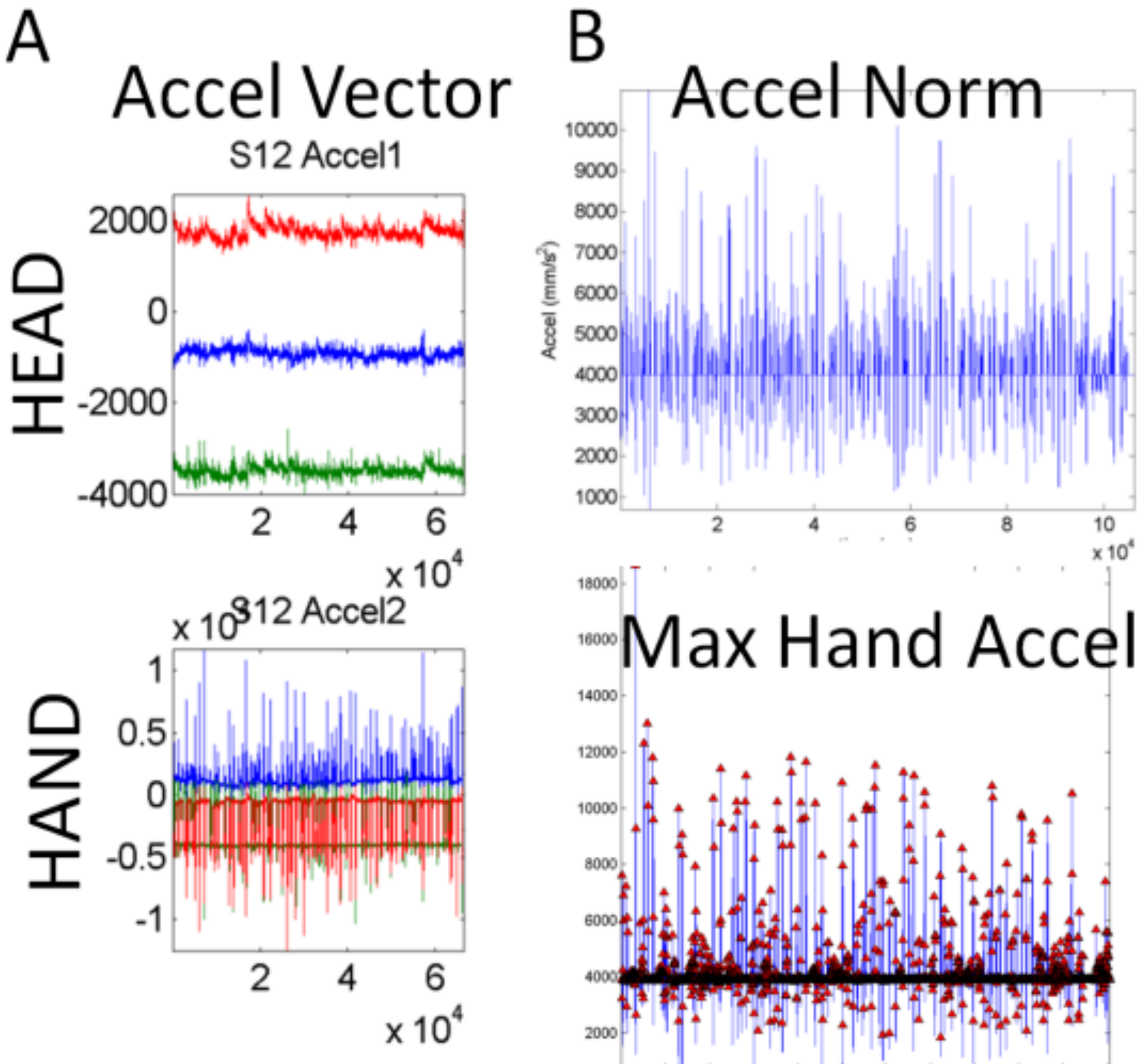

PARSING MOVEMENT CLASSES

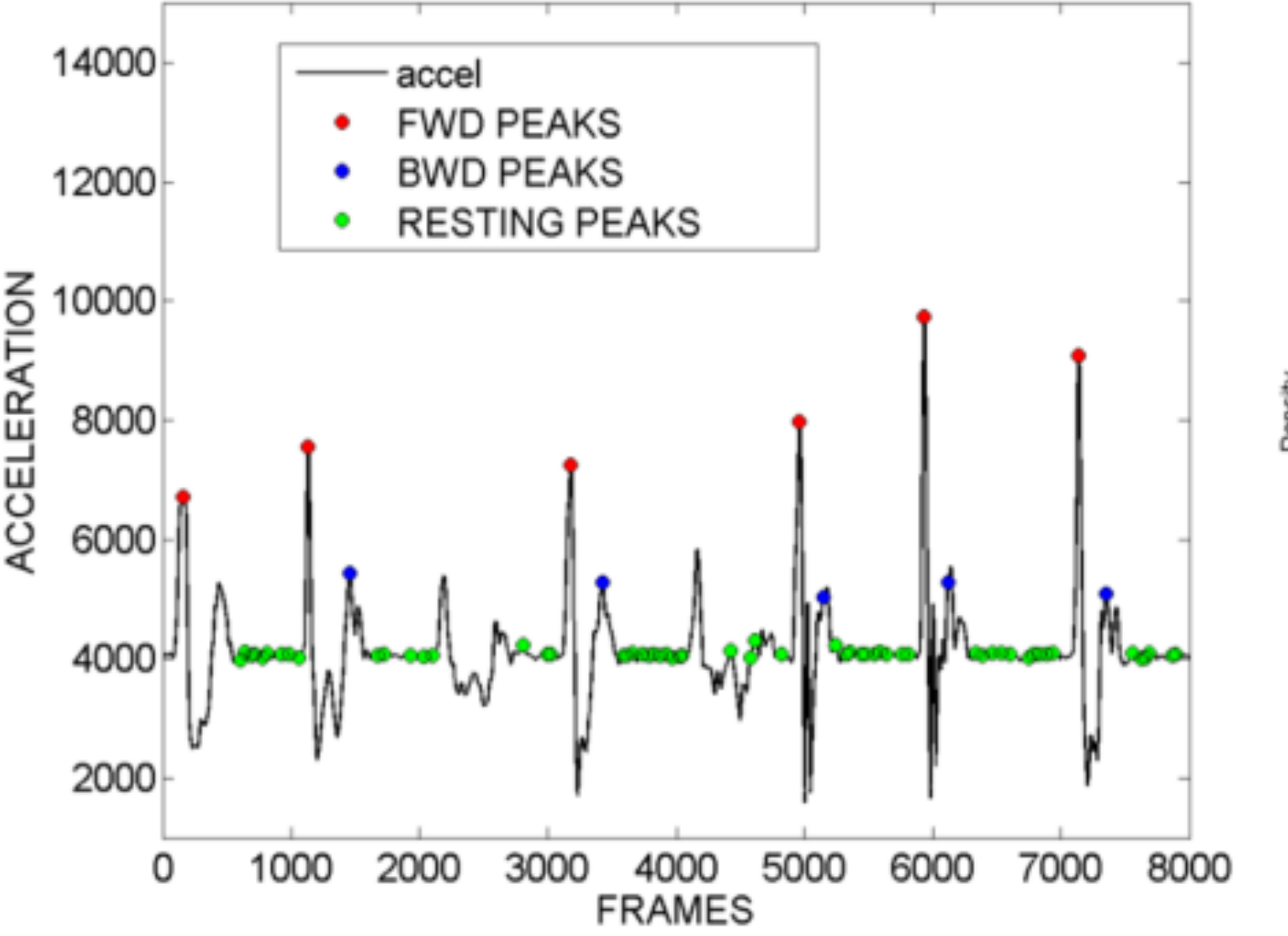

Centre National de la Recherché Scientifique

Paris, France
Asaf Bachrach

\section{Results \& Analysis}

In Figure 1A, the top graph plots data from the accelerometer mounted on one sample subject's head, and the bottom graph plots the same for the accelerometer on the subject's pointing hand. Data is automatically parsed between forward pointing segment (blue), retraction (red), and rest (green). All three segments of the gesture were performed faster in the afternoon session compared to the morning (Figure 1D). Further analysis and control experiments will be required to determine whether this acceleration was due to the dance training.

We used a Gamma function family to estimate the distribution of the values of the acceleration peaks by segment and session (Figure 1C). Peak acceleration fluctuations across trials for each individual have distinct stochastic signatures. The empirical frequency distributions of such parameters can be used to estimate the two Ganima parameters that un parameter values

(Figure 2A) provides a visualization of the relative predictive-ness (growing from left to right) and noise (decreasing from top to bottom) of each segment regarding the next trial (by individual and by session).

The three segments are clearly distinguishable by their Gamma parameters, the pointing motion being the most variable (least predictive), and the survising had a the randomly instructed speed, which,

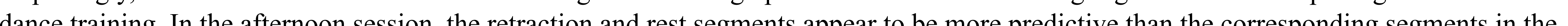
morning session. We hypothesize that this increase is the result of Myriam Gourfink's specific training, enhancing continuous conscious awareness of body and movement state. We are currently conducting additional analyses to verify this conclusion.

\section{References}

2003. Contact Quarterly interview. (Winter-Spring 2003). Retrieved February 18 2014, from http://ww [2] Torres, E.B. 2013. Signatures of movement variability anticipate hand speed according to levels of intent. Behavioral and Brain Functions. 9, 10. DOI= $10.1186 / 1744-9081-9-10$ [3] Torres, E.B. 2011. Two classes of movements in motor control. Exp Brain Res 215:269-283. (Oct 2011). DOI= 10.1007/s00221-011-2892-8 (5) Tres, E.B., Brincker. M., et al. 2013. Autism: the micro-movement perspective. Front. Integr. Neurosci. 7, 32. (July 2013). DOI= 10.3389/fnint.2013. Disorders. Rutgers University Patent US Pending 2012-051, 